WEI LUO, Ph.D. Candidate ${ }^{1}$

E-mail: Iuoweibjut@163.com

LISHAN SUN, Ph.D. ${ }^{1}$

E-mail: Issun@bjut.edu.cn

LIYA YAO, Ph.D. ${ }^{2}$

(Corresponding author)

E-mail: yaoliya@bit.edu.cn

QINGSHENG GONG ${ }^{1}$

E-mail: gqsgentleman@sina.com

JIAN RONG, Ph.D. ${ }^{1}$

E-mail: jrong@bjut.edu.cn

${ }^{1}$ Beijing Key Laboratory of Traffic Engineering

Beijing University of Technology

100 Pingleyuan, Chaoyang District, Beijing, 100124,

China

${ }^{2}$ School of Mechanical and Vehicular Engineering

Beijing Institute of Technology

5 South Zhongguancun Street, Haidian District,

Beijing, 100081, China
Science in Traffic and Transport

Original Scientific Paper

Submitted: 30 Aug 2017

Accepted: 12 Apr 2018

\title{
EXPERIMENTAL STUDY FOR OPTIMIZING PEDESTRIAN FLOWS AT BOTTLENECKS OF SUBWAY STATIONS
}

\begin{abstract}
In subway stations, bottlenecks are the narrowed areas that reduce pedestrian flows in channels. Because pedestrians at bottlenecks are forced to dense together, bottlenecks decrease flow efficiency and pedestrians' transfer comfort and may trigger serious crowd disasters such as trampling. This study used pedestrian experiments to investigate the methods of optimizing pedestrian traffic at bottlenecks of subway stations. Three optimization measures were proposed and evaluated by analyzing the characteristics of pedestrian flows, including efficiency, smoothness, and security. In this paper, setting the rear sides of the bottleneck entrance as straight and surface funnel shapes is called straight funnel shape and surface funnel shape, respectively. Setting a column at a bottleneck is called the column obstacle. The results showed that when efficiency or security come first, a column on the left is recommended; when comfort comes first, a concave funnel is recommended; when comprehensiveness is prioritized, a column on the left is recommended. Moreover, the larger the volume, the optimization is more obvious. Although many bottlenecks cannot be prevented when subway stations are constructed, the proposed optimization measures may help ease their adverse effects by improving facility efficiency, smoothness, and security, and by providing recommendations for designing and managing subway stations.
\end{abstract}

\section{KEY WORDS}

subway station; bottleneck; optimization measure; pedestrian characteristic; pedestrian experiment;

\section{INTRODUCTION}

In Beijing, the subway has been the primary type of public transportation, accounting for $45 \%$ of public transport in 2014 and carrying more than 11 million passengers daily on average [1]. In subway stations, bottlenecks are the narrowed areas that reduce pedestrian flows in channels. Because pedestrians are forced to dense together, bottlenecks decrease flow efficiency and pedestrians' transfer comfort and may trigger serious crowd disasters such as trampling. How to decrease (and even avoid) the adverse effects of bottlenecks to make pedestrians walk through in a fast and efficient manner has been a new task for subway operational management, particularly for those subway stations with regularly high volumes at traffic peaks. This study investigates the optimization methods for pedestrian flows at bottlenecks of subway stations.

Studies have characterized pedestrian behaviors, especially those at bottlenecks. Helbing and Molnar discussed two instances, using two doors and using a roundabout, for improving the standard elements of pedestrian facilities [2]. Bolay suggested that a funnel-shaped construction could improve pedestrian flow at bottlenecks [3]. Helbing et al. also investigated the mechanisms of panic and jamming at bottlenecks by a model of pedestrian behavior and suggested practical ways to prevent dangerous crowd pressures [4]. Helbing and Molnar further found that the flow at 
bottlenecks could be improved by expanding a funnel-shaped space in the bottleneck construction [5]. Daamen and Hoogendoorn designed pedestrian experiments to study the effects of free speed, walking direction, density, and bottlenecks on the characteristics of a pedestrian flow passing a bottleneck [6]. Hoogendoorn and Daamen also used pedestrian experiments to identify the zipper effect at a bottleneck, determining that the capacity of the bottleneck increased in a stepwise fashion with the increasing width of the bottleneck less than $3 \mathrm{~m}$ [7]. Kretz et al. conducted pedestrian experiments, finding the difference between narrow (one person at a time) and wide bottlenecks (two persons at a time) in the distribution of time gaps [8]. Considering the effect of a psychological phenomenon, Kretz et al. also identified the relationship between pedestrian flow and bottleneck width [9]. Seyfried et al. compared the findings of bottleneck pedestrian experiments from different researchers, concluding that the jam would occur even with the incoming flow lower than the capacity [10]. Guo proposed a revised social force model to simulate the pedestrian counter flow through a bottleneck. This model could reproduce self-organizing movement patterns of pedestrian flow, such as oscillatory flow and three classes (unidirectional, mixed, and separate) of lane formations [11]. Li and Han proposed a pedestrian evacuation simulation model based on extended cellular automata to study pedestrian behavior effects at bottlenecks. It was found that either a highly conservative behavior or a highly aggressive behavior could slow down evacuations [12]. Liao et al. (2016) proposed a modified version of the cumulative sum control chart algorithm, which could robustly detect steady states from density and speed time series of bottleneck experiments [13]. Sun proposed a dynamic time warping (DTW) algorithm for identifying, analyzing, and verifying the shockwaves at bottlenecks [14]. Through a pedestrian experiment, Shiwakoti found that the merging angle has influence on the pedestrian flow [15]. A new study by Sun [16] found that the funnel shape effectively improves traffic efficiency at bottlenecks, especially under large volumes. New breakthroughs have been made in optimizing pedestrian bottlenecks.

Scholars have made some progress in this field, especially in terms of suggestions to improve pedestrian performance at bottlenecks. However, a comprehensive and in-depth study on optimizing pedestrian flows at bottlenecks is still lacking. Based on other research, this study used pedestrian experiments to explore the feasibility and effects of optimization measures at bottlenecks of subway stations. The types of the optimization measures were the straight funnel shape, the surface funnel shape, and the column obstacle. Section 2 analyzes real-world pedestrian characteristics at bottlenecks based on video footage taken at Beijing subway stations. Section 3 describes the controlled pedestrian experiment. Section 4 lists the analytical results of pedestrian flow characteristics with different types of optimization measures at bottlenecks. Section 5 provides conclusions and recommendations for future research.

\section{ANALYSIS OF PEDESTRIAN CHARACTERISTICS AT BOTTLENECKS}

\subsection{Pedestrian characteristics at bottlenecks}

This study first conducted field research for observing pedestrian walking characteristics at a bottleneck in a weekday morning rush hour (7-8 a.m.). A digital camera placed in the plafond was used to analyze pedestrian behavior. SIMI Motion was used for motion capture. Video footage at a bottleneck of unidirectional flow at Guomao subway station was taken and analyzed [17].

Figure 1 shows the gradient of instantaneous speed at the bottleneck. It was observed that pedestrian speed decreased when pedestrians approached the

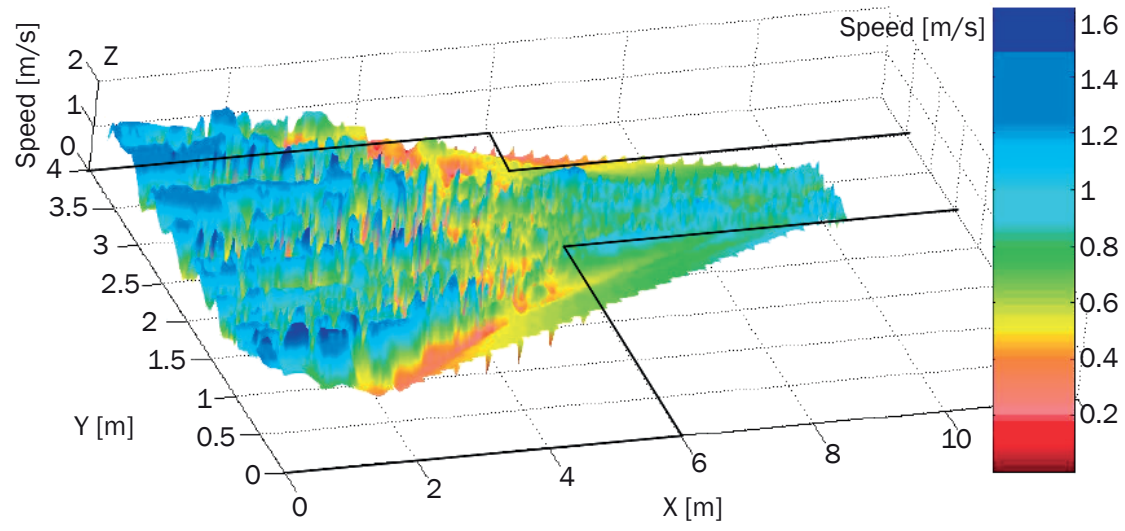

Figure 1 - Speeds (in z-direction) for the bottleneck example in Beijing subway [16] Pedestrians walk from left $(x=0 \mathrm{~m})$ to right $(x=10 \mathrm{~m})$ 
Table 1 - Descriptive statistics of pedestrian speed

\begin{tabular}{||c|c|c|c|c|c||}
\hline Observation region & $\begin{array}{c}\text { Mean } \\
{[\mathrm{m} / \mathrm{s}]}\end{array}$ & $\begin{array}{c}\text { Medium } \\
{[\mathrm{m} / \mathrm{s}]}\end{array}$ & $\begin{array}{c}\text { Max } \\
{[\mathrm{m} / \mathrm{s}]}\end{array}$ & $\begin{array}{c}\text { Min } \\
{[\mathrm{m} / \mathrm{s}]}\end{array}$ & $\begin{array}{c}\text { Standard } \\
\text { deviation }\end{array}$ \\
\hline \hline $\begin{array}{c}\text { Before the bottleneck } \\
(0<\mathrm{x}<4)\end{array}$ & 0.75 & 0.66 & 1.63 & 0.02 & 0.31 \\
\hline $\begin{array}{c}\text { Before the bottleneck } \\
(4<\mathrm{x}<6)\end{array}$ & 0.51 & 0.49 & 1.51 & 0.01 & 0.24 \\
\hline $\begin{array}{c}\text { Bottleneck corridor } \\
(6<x<10)\end{array}$ & 0.88 & 0.84 & 1.47 & 0.18 & 0.16 \\
\hline
\end{tabular}

influx and that a slight recovery occurred after pedestrians entered the bottleneck. Pedestrians who were far away from the bottleneck walked at a high speed. In addition, pedestrian speeds varied greatly before entering the bottleneck but became stable after pedestrians entered the bottleneck. Table 1 lists the descriptive statistics of pedestrian speed. The average pedestrian speed in the bottleneck $(4<x<6)$ was about $42 \%$ faster than at the bottleneck entrance $(6<x<10)$, which can be partially explained by psychological effects caused by built environment [18-22]. Thus, improving pedestrian speed at the entrance of the bottleneck is important.

Additionally, three phenomena of pedestrian flows at bottlenecks were found through observing the video footage.

Individual pathfinding. Since the pedestrian flow speed at the bottleneck was low, a long pedestrian queue waited at the front of the bottleneck entrance, and, meanwhile, part of the pedestrian crowd stood around the two rear sides of the bottleneck entrance. That is, pedestrians made a choice on different routes entering the bottleneck. This study refers to the phenomenon of route choice behavior [23] as "individual pathfinding" (Figure 2a). After investigating 32 bottlenecks at the Guomao subway station in Beijing, individual pathfinding occurred 577 times during the observation period (7-9 a.m.), its total occurrence rate amounting up to $90 \%$. In the individual pathfinding, pedestrian flow was divided into three shares according to the choice of pedestrian path; the speed of pedestrians in the two rear sides was significantly higher (approximately $20 \%$ ) than in the frontal side. There were about $20 \%$ more pedestrians on the right rear side than on the left rear side. This might be caused by the right-hand traffic in China. Three flows of pedestrian pressure were applied at the bottleneck at the same time, which leads to competitive behavior. The front pedestrian flow and two rear side pedestrian flows were mutually extruded, forming arch congestion or the so-called "arc clogging" at the bottleneck. In the process of individual pathfinding, pedestrians' expected speed is higher, and the likelihood of arch congestion is greater. With alower access rate, the actual speed is lower, forming the "fast-is-slow effect" [4]. Individual pathfinding causes pedestrian flow disequilibrium, which aggravates the jams. It is necessary to reduce the occurrences of individual pathfinding.

Space angle. As shown in Figure $2 b$, an empty area with the shape of a right-angled triangle existed at each rear side of the bottleneck entrance, so that the pedestrian flow outside of the bottleneck entrance presented a funnel-shape. We called this phenomenon the "space angle", similar to the principles of "border effect" [24]. Because of the right-hand traffic in China, the space angle was less likely to appear on the right, about $11 \%$, as opposed to about $93 \%$ on the left. The values of the space angles under different scenarios were different. When the space angle occurred, the distribution of pedestrian density was uneven near the bottleneck entrance.

Pedestrian arching effect. Due to the imbalance of the arrival and departure rates at the bottleneck (i.e., more arrivals than departures), the pedestrian flow had the shape of a circular arch, referred to as the "arching phenomenon" [4, 7, 10, 25]. Figure $2 c$ shows the process of pedestrian arching and dissipation. Because of the periodicity of arrivals in the rail transit hub, the

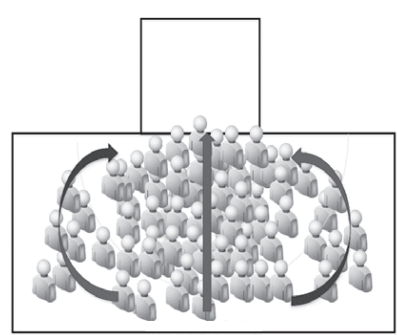

a) Schematic diagram of individual pathfinding phenomenon at a bottleneck

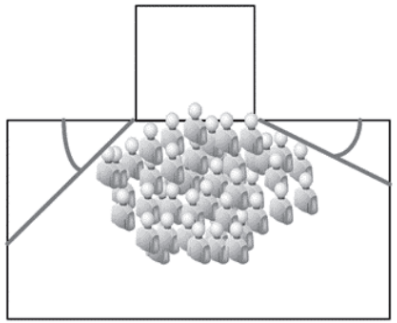

b) Schematic diagram of pedestrian space angle

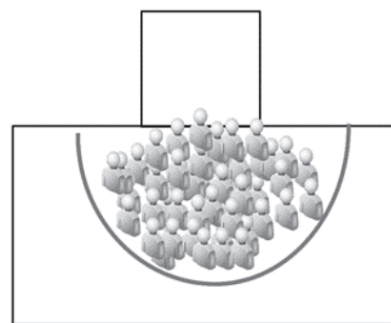

c) Pedestrian arching and dissipation process

Figure 2 - Three phenomena of pedestrian flows at bottlenecks 


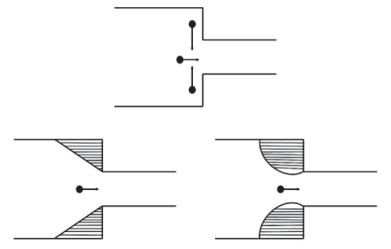

a) Funnel shape principle

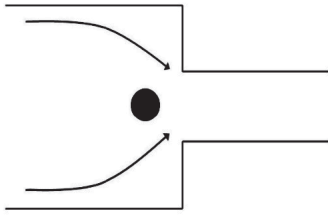

b) Column obstacle principle

Figure 3 - Principles of measures

density of pedestrian flow varied periodically. When pedestrian flow density was moderate, the pedestrian flow in front of the bottleneck entrance was structured as a queue. When the density was high, the pedestrians who waited in front of the bottleneck entrance began to form a crowd with the circular arch shape. The pedestrian crowd gradually dissipated until reaching a certain length. In the process of circular arch forming, the interaction forces between the pedestrians in the arch were transmitted. The circular arch blocked pedestrians from passing through the bottleneck and might have caused a stampede.

\subsection{Proposal ofoptimization measures}

According to the characteristics of pedestrian flows at bottlenecks, the optimization measures of straight funnel shape, surface funnel shape, and column obstacle are proposed. In Figure 3a, the measures of setting the rear sides of the bottleneck entrance as the straight funnel shape and the surface funnel shape are used to reduce the conflicts caused by the individual pathfinding and the space angle. Helbing et al. [5] and Bolay [3] proposed that a funnel-shaped construction was capable of improving the pedestrian flow at bottlenecks by guiding the pedestrian flow to avoid pedestrian conflicts. However, detailed quantitative data and optimal funnel angles have been not studied. As shown in Figure $3 b$, the measure of setting a column obstacle at a bottleneck is used to avoid the formation of the pedestrian arching effect. For improving pedestrian outflows, Helbing recommended placing columns asymmetrically in front of the exit to prevent fatal buildup pressures [4].

\section{PEDESTRIAN EXPERIMENTS}

Collecting data from videos of subway stations is difficult because of the limited space and the subway environment's complexity. Besides, in Beijing subway stations that have busy traffic, controlling pedestrian flows and setting measures for experiments is challenging. Pedestrian experiments have been widely used in pedestrian studies [5-11, 17, 26-28]. Hence, the controlled pedestrian experiments at scene buildings were taken as the research method to analyze optimization measures in the subway. Through the experiments, the movement behaviors of pedestrians in the experiment scenes (i.e., the pedestrian movement parameters and walking rules) were determined.

\section{Fundamentals of the experiment}

The pedestrian experiments were conducted at the Beijing University of Technology on 17 April 2015. The weather was sunny, moderately windy. The experiments were carried out in the teaching building, which had enough experiment space and a wide vision angle (for camera convenience). The experimental site was horizontal, no slope. The ambient conditions were favorable (reasonably constant light intensity, few shadows, smooth surface). A pixel camera with a resolution of $1920 \times 1080$, adequate for analyzing the speed and position change of pedestrians [29], was set up vertically (20 meters above the ground).The SIMI Motion software application, which employs novel algorithms to process video footage, was used for motion capture in this study.

\section{Geometrical layout of the experiment field}

The experimental scene design was referenced from Hoogendoorn and Daamen [7], Seyfried et al. [10], Seyfried et al. [27], and Yang et al. [30]. As shown in Figure 4, the bottleneck width was $1 \mathrm{~m}$, the typical width of bottlenecks in Beijing subway stations (e.g., escalator entrance). A corridor with a width of $5 \mathrm{~m}$ and height of $2 \mathrm{~m}$ (higher than the tallest participant, $181 \mathrm{~cm}$ tall) was simulated using artificial walls, which in turn prevents the change of the effective width of the bottleneck. The pedestrians walked along the direction of the $X$ axis. The experimental scene was divided into a trial region and a preparation region. The

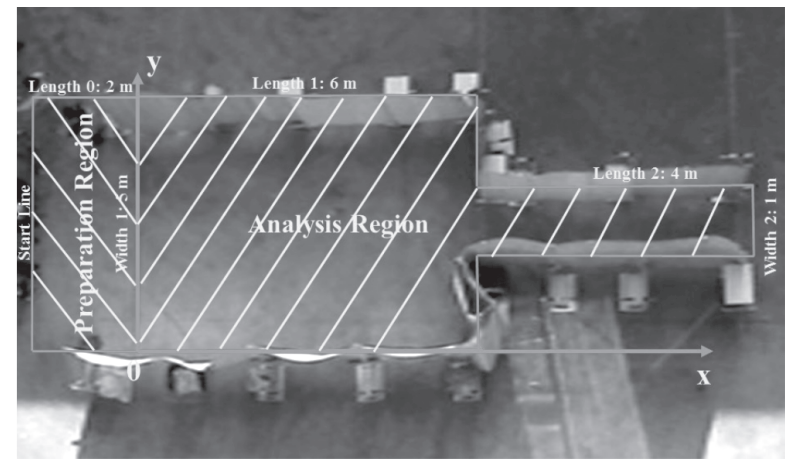

Figure 4 - Setting of optimization measures 
trial region for experimental analysis was $6 \times 5 \mathrm{~m}$ and $4 \times 1 \mathrm{~m}$. The preparation region provided to ensure participants were in random and natural state for each walk was $5 \times 2 \mathrm{~m}$, similar to the experimental settings in Seyfried et al. [10, 27] and Yang et al. [30]. Being consistent with the field study at the subway station, the distance from preparation region to the bottleneck entrance was $6 \mathrm{~m}$, which is long enough to analyze pedestrian movements and longer than the one in Seyfried et al. [10, 27].

\section{Experiment scenarios}

The optimization measures of this study were straight funnel shape, surface funnel shape, and column obstacle. As shown in Figure 5, we set the slopes of the funnel shape as $30^{\circ}, 45^{\circ}, 60^{\circ}$, and $90^{\circ}$. The surface funnel shape was divided into the concave and convex. The obstacle columns were placed in the middle, on the right, and on the left, and the diameter of obstacle columns was $0.3 \mathrm{~m}$. The height of the four measures was $1.1 \mathrm{~m}$, the same as the guardrail in Beijing subway.

According to the definition in TRB's Transit Cooperative Research Program (TCRP) Report 100: Transit Capacity and Quality of Service Manual, the standard one-direction passageway capacity is 5,000 person $/ \mathrm{h} / \mathrm{m}$ [31]. The pedestrian volumes were achieved by controlling the pedestrian flow rate entering the bottleneck. Hence, three levels of pedestrian volumes were experimented in this research: 4,000 person/h/m, 5,000 person/h/m, 6,000 person/h/m, which corresponded to 6,7 , and 8 participants

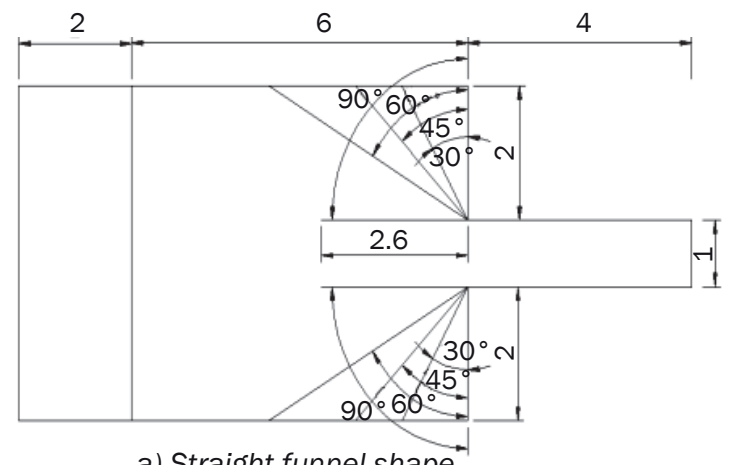

a) Straight funnel shape

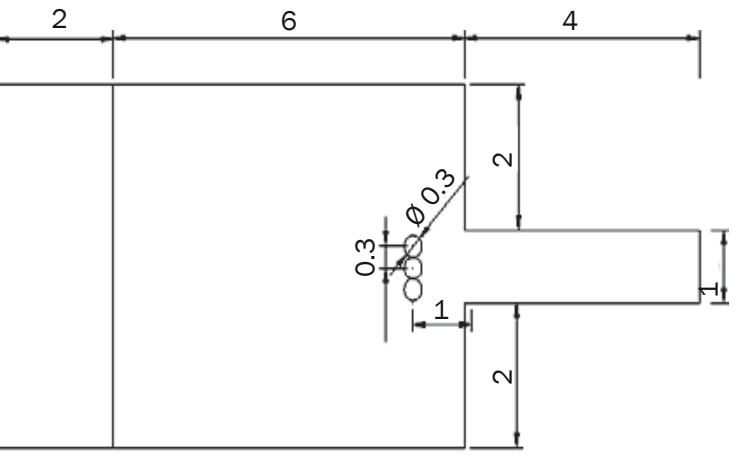

c) Column obstacle

Figure 5 - Setting of optimization measures entering the preparation region per second, respectively. This arrangement ensured that flow volume changed effectively. A total of 30 scenarios were set up for analysis, as listed in Table 2. In Table 2, "none" (blank control group) means there are no optimization measures in the scenario.

\section{Experiment participants and training}

The participants were 50 healthy undergraduate students, including 27 males and 23 females. The participants were selected from different classes and departments to minimize the acquaintance among students. The ages were between 18 to 25 years old, and the heights were between $160 \mathrm{~cm}$ and $181 \mathrm{~cm}$. The average age and the average height was 22 years old, and $169.38 \mathrm{~cm}$; the standard deviations of the ages and the heights were 2.05 years and $6.82 \mathrm{~cm}$. The participants were asked to wear colorful hats, which helped to better detect and track pedestrians in the post-processing of video data.

Before the experiments, an instruction on the rules and purposes of the experiments was provided to the participants. In each experimental trial, the participants were randomly queued in front of the yellow start line. This randomization would prevent the participants from obtaining learning behaviors during the trials. The participants were required to walk as in an actual situation in the subway station. There was no stop phenomenon when the participants walked through the bottleneck corridor. In addition, to ensure the results of experiments would be close to reality, each volume was experimented for 3 times.

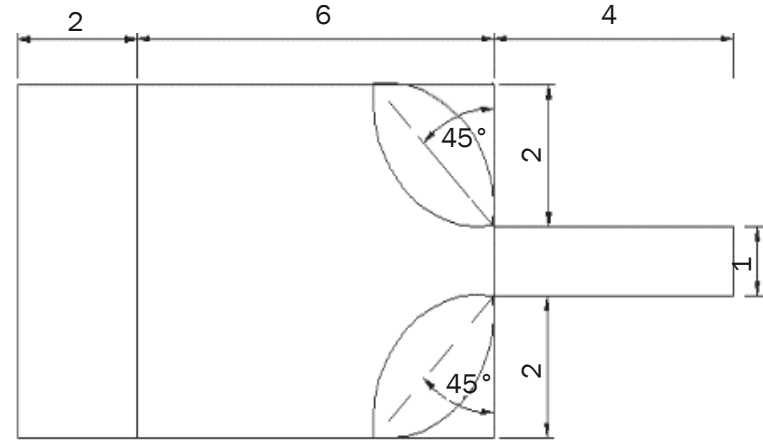

b) Surface funnel shape 
Table 2 - Experiments scenario configurations

\begin{tabular}{|c|c|c|c|c|c|c|c|}
\hline $\begin{array}{l}\text { Optimization } \\
\text { measures }\end{array}$ & Scenario & Settings & $\begin{array}{l}\text { Volume } \\
{[\mathrm{p} / \mathrm{h} / \mathrm{m}]}\end{array}$ & $\begin{array}{l}\text { Optimization } \\
\text { measures }\end{array}$ & Scenario & Settings & $\begin{array}{l}\text { Volume } \\
{[\mathrm{p} / \mathrm{h} / \mathrm{m}]}\end{array}$ \\
\hline \multirow{3}{*}{$\begin{array}{c}\text { None } \\
\text { (Blank control group) }\end{array}$} & $0-1 a$ & \multirow{3}{*}{-} & 4,000 & \multirow{6}{*}{$\begin{array}{l}\text { Surface funnel } \\
\text { shape }\end{array}$} & $2-1 a$ & \multirow{3}{*}{ Concave } & 4,000 \\
\hline & $0-1 b$ & & 5,000 & & $2-1 b$ & & 5,000 \\
\hline & $0-1 c$ & & 6,000 & & $2-1 c$ & & 6,000 \\
\hline \multirow{12}{*}{$\begin{array}{l}\text { Straight Funnel } \\
\text { Shape }\end{array}$} & $1-1 a$ & \multirow{3}{*}{$30^{\circ}$} & 4,000 & & $2-2 a$ & \multirow{3}{*}{ Convex } & 4,000 \\
\hline & $1-1 b$ & & 5,000 & & $2-2 b$ & & 5,000 \\
\hline & $1-1 c$ & & 6,000 & & $2-2 c$ & & 6,000 \\
\hline & $1-2 a$ & \multirow{3}{*}{$45^{\circ}$} & 4,000 & \multirow{9}{*}{$\begin{array}{l}\text { Column } \\
\text { obstacle }\end{array}$} & 3-1a & \multirow{3}{*}{$\begin{array}{l}\text { Column in } \\
\text { the middle }\end{array}$} & 4,000 \\
\hline & $1-2 b$ & & 5,000 & & 3-1b & & 5,000 \\
\hline & $1-2 c$ & & 6,000 & & $3-1 c$ & & 6,000 \\
\hline & $1-3 a$ & \multirow{3}{*}{$60^{\circ}$} & 4,000 & & $3-2 a$ & \multirow{3}{*}{$\begin{array}{l}\text { Column on } \\
\text { the right }\end{array}$} & 4,000 \\
\hline & $1-3 b$ & & 5,000 & & $3-2 b$ & & 5,000 \\
\hline & $1-3 c$ & & 6,000 & & $3-2 c$ & & 6,000 \\
\hline & $1-4 a$ & \multirow{3}{*}{$90^{\circ}$} & 4,000 & & $3-3 a$ & \multirow{3}{*}{$\begin{array}{l}\text { Column on } \\
\text { the left }\end{array}$} & 4,000 \\
\hline & $1-4 b$ & & 5,000 & & $3-3 b$ & & 5,000 \\
\hline & $1-4 c$ & & 6,000 & & $3-3 c$ & & 6,000 \\
\hline
\end{tabular}

\section{RESULTS AND ANALYSIS}

\subsection{Evaluation index}

Evaluation indexes, which are related to pedestrian flows' efficiency, smoothness, and security, were defined for evaluating the optimization measures.

\section{Efficiency}

The total passing time, an indicator of the overall efficiency of pedestrian flows, is defined as the time from the first pedestrian entering the trial region to the last pedestrian leaving the trial region:

$T=t_{n d}-t_{1 e}$

where $T$ is the total passing time (s), $t_{1 d}$ is the time of the first pedestrian entering the trial region, and $t_{n d}$ is the time of the last pedestrian leaving the trial region.

The traffic efficiency at the exit of the bottleneck, which reflects the passing efficiency at the bottleneck region, is defined as the number of people over a unit width leaving the exit in a time interval:

$$
\begin{aligned}
E & =\frac{3600}{t} \cdot \frac{n}{w} \\
& =\frac{3600}{t_{n d}-t_{1 d}} \cdot \frac{n}{w}
\end{aligned}
$$

where $E$ is the pedestrian flow traffic efficiency at exit $(\mathrm{p} / \mathrm{h} / \mathrm{m}), t$ is the time of the whole pedestrian flow passing the exit (s), $n$ is the total number of pedestrians, and $w$ is the exit width $(\mathrm{m})$.

\section{Smoothness}

The smoothness of speed reflects the frequency and degree of velocity variation, i.e., the level of discontinuity of walking due to necessary avoidance maneuvers.
$U=\frac{1}{N} \sum_{\alpha} \frac{\overline{\left(\vec{v}_{\alpha}-\vec{v}_{\alpha}\right)^{2}}}{\left(\vec{v}_{\alpha}\right)^{2}}(0 \leq U \leq 1)$

where $U$ is smoothness of speed, $\overline{\vec{v}_{\alpha}}$ is pedestrians' space speed $(\mathrm{m} / \mathrm{s})$, which means the ratio of distance to time in a certain space, and $\vec{v}_{\alpha}$ is pedestrian' instantaneous speed (m/s), which means the speed of a pedestrian through a certain point.

Pedestrians tend to walk in areas with low pedestrian density and few crossings, looking to complete activities in the shortest possible time. Meanwhile, due to the inertia theorem, the lower the frequency and degree of speed change, the less strength each stride will take. The acceleration and deceleration process will consume a certain amount of physical strength. Hence, a smaller index value means more comfortable pedestrian distribution.

Considering the complexity of facilities and environment, pedestrians do not always walk the shortest distance. The distance curve coefficient is defined as the ratio of walking distance to the shortest linear distance, indicating smoothness and stability:

$$
R=\frac{l}{d}
$$

where $R$ is distance curve coefficient, $l$ is actual walking distance $(\mathrm{m})$, and $d$ is the shortest linear distance (m).

The value of $R$ is in the range of $[1,1.5]$; if it is above this range, pedestrians will generate undesirable sentiments, leading to decreased stability and security due to excessive walking distance [32].

\section{Security}

The spatial chaos coefficient refers to the degree of change of the regional average density to pedestrian flow. This index mainly investigates the possibility of 
regional crowding. Clearly, the trend of regional density varies with pedestrian scale, which reflects a significant tendency of saturation and could be regarded as one of the indicators of security problems [32].

$T_{u_{s}}=\frac{\frac{D_{\text {ave }\left(t+t_{0}\right)}^{s}}{D_{\text {ave }(t)}}}{\frac{Q_{\left(t+t_{0}\right)}}{Q(t)}}$

where $T_{u_{s}}$ is the spatial chaos coefficient, $D_{\text {ave }\left(t+t_{0}\right)}^{s}$ is the regional average density at time $t+t_{0}$ $\left(\mathrm{p} / \mathrm{m}^{2}\right), D_{\text {ave }(t)}^{s}$ is the regional average density at time $t(\mathrm{p} / \mathrm{m} 2), Q_{\left(t+t_{0}\right)}$ is the pedestrian flow at $t+t_{0}$ time $(\mathrm{p} / \mathrm{h} / \mathrm{m}), Q_{(t)}$ is the pedestrian flow at $t$ time $(\mathrm{p} / \mathrm{h} / \mathrm{m})$, and $t_{0}$ is interval time.

Non-uniformity of congestion spatial distribution indicates the state of congestion spatial distribution in different scenarios at the same time [32].

$S_{v}^{c}=\left[\frac{D_{\text {max }}^{s}-D_{\text {ave }}^{s}}{D_{\text {ave }}^{s}}\right]^{2}$

where $S_{v}^{c}$ is non-uniformity of spatial congestion distribution, $D_{\max }^{s}$ is density in the most crowded area, $\left(\mathrm{p} / \mathrm{m}^{2}\right)$, and $D_{\text {ave }}^{s}$ is the regional average density, $\left(p / m^{2}\right)$.

\subsection{Straight funnel shape}

Figures 6a-6f show the efficiency, comfort, and security of the straight funnel shape under different volumes, respectively, and the different scatter values represent different volumes. Under all volumes, with an increase of the funnel angle, the total passing time tended to first decrease and then increase. With passenger flow increase, the total passing time increases as well. Under 4,000 p/m/h, 5,000 p/m/h, and 6,000 $\mathrm{p} / \mathrm{m} / \mathrm{h}$, the minimum values of the total passing time of the straight funnel shape (at $45^{\circ}$ ) were $2.15 \%$, $5.18 \%$, and $6.59 \%$ lower than the ones of the blank control group. The traffic efficiency at exit presented a different pattern. Under $4,000 \mathrm{p} / \mathrm{m} / \mathrm{h}$ and 5,000 $\mathrm{p} / \mathrm{m} / \mathrm{h}$, the straight funnel shape had no positive effect. Only at $6,000 \mathrm{p} / \mathrm{m} / \mathrm{h}$ did the traffic efficiency values at exit reach the highest points under the $30^{\circ}$ and $45^{\circ}$ funnel scenarios, being $6.27 \%$ and $6.27 \%$ higher than the those of the blank control group. This interesting phenomenon indicates that optimization measures only increase traffic efficiency at exit under large volumes $(6,000 \mathrm{p} / \mathrm{h} / \mathrm{m})$. The greater the volume, the more obvious the optimization effect. That is to say, taking such measures under the volume of 6,000 $\mathrm{p} / \mathrm{h} / \mathrm{m}$ can improve traffic efficiency at exit more than under 4,000 p/h/m and 5,000 p/h/m. Meanwhile, the total number of participants is fixed, 50 students. The fixed number of participants and different input volumes result in the fact that little improvement of traffic efficiency will be obvious. This resulted in a higher traffic efficiency at $6,000 \mathrm{p} / \mathrm{h} / \mathrm{m}$ than with the input volumes of $4,000 \mathrm{p} / \mathrm{h} / \mathrm{m}$ and $5,000 \mathrm{p} / \mathrm{h} / \mathrm{m}$ under the $30^{\circ}, 45^{\circ}$, and $60^{\circ}$ funnel shapes.

Under all volumes, with the increase of the funnel angle, the smoothness of speed tended to decrease first, then increase, and thereafter decrease again. The smoothness of speed changes much more under a small passenger flow. Under 4,000 p/m/h, 5,000 $\mathrm{p} / \mathrm{m} / \mathrm{h}$, and $6,000 \mathrm{p} / \mathrm{m} / \mathrm{h}$, the smoothness of speed reached the lowest values at the $45^{\circ}$ funnel, that is, $7.47 \%, 4.69 \%$, and $3.95 \%$ lower than the one of the blank control group. As an extension of the guardrail, due to the area which pedestrian can bypass is narrowed, the distance curve coefficients are all low under the three volumes. Under 4,000 p/m/h and 6,000 $\mathrm{p} / \mathrm{m} / \mathrm{h}$ the distance curve coefficient reached the lowest point at the $90^{\circ}$ funnel, $1.22 \%$ and $1.87 \%$ lower than blank control group, respectively. Under 5,000 $\mathrm{p} / \mathrm{m} / \mathrm{h}$ it reached the lowest point at the $45^{\circ}$ funnel, $1.13 \%$ lower than blank control group.

Under all volumes, with the increase of funnel angle, the spatial chaos coefficient and non-uniformity of congestion spatial distribution first presented a decreasing and then an increasing trend. Under 4,000 $\mathrm{p} / \mathrm{m} / \mathrm{h}$ and $5,000 \mathrm{p} / \mathrm{m} / \mathrm{h}$ the spatial chaos coefficient reaches the lowest point at the $45^{\circ}$ funnel, $2.99 \%$ and $5.94 \%$ lower than the blank control group, respectively. Under $6,000 \mathrm{p} / \mathrm{m} / \mathrm{hit}$ reaches the lowest point at the $60^{\circ}$ funnel, $7 \%$ lower than the blank control group. The non-uniformity of congestion spatial distribution reaches the lowest point at the $45^{\circ}$ funnel, 0.32\%, $7.66 \%$ and $9.72 \%$ lower than blank control group un$\operatorname{der} 4,000 \mathrm{p} / \mathrm{m} / \mathrm{h}, 5,000 \mathrm{p} / \mathrm{m} / \mathrm{h}$ and $6,000 \mathrm{p} / \mathrm{m} / \mathrm{h}$, respectively. The larger the volume, the greater the decrease of the spatial chaos coefficient and non-uniformity of congestion spatial distribution.

\subsection{Surface funnel shape}

Figures $7 a-7 f$ show the efficiency, comfort, and security of the surface funnel shape under different volumes, respectively, and the different scatter values represent different volumes. It is clear that, regardless of volume, the total passing time is lower than the blank control group at concave and convex funnels. In addition, the total passing time at the concave funnel changes more, i.e., it is 5.52\%, 6.12\%, and 6.89\% lower than the blank control group under $4,000 \mathrm{p} / \mathrm{m} / \mathrm{h}$, $5,000 \mathrm{p} / \mathrm{m} / \mathrm{h}$, and $6,000 \mathrm{p} / \mathrm{m} / \mathrm{h}$, respectively. The greater the volume, the greater the degree of total passing time reduction. Only the concave funnel has a positive effect on traffic efficiency at exit, which is higher than the blank control group under $4,000 \mathrm{p} / \mathrm{m} / \mathrm{h}$ and $5,000 \mathrm{p} / \mathrm{m} / \mathrm{h}$, i.e., $1.40 \%$ and $4.90 \%$ higher than the blank control group, respectively. 


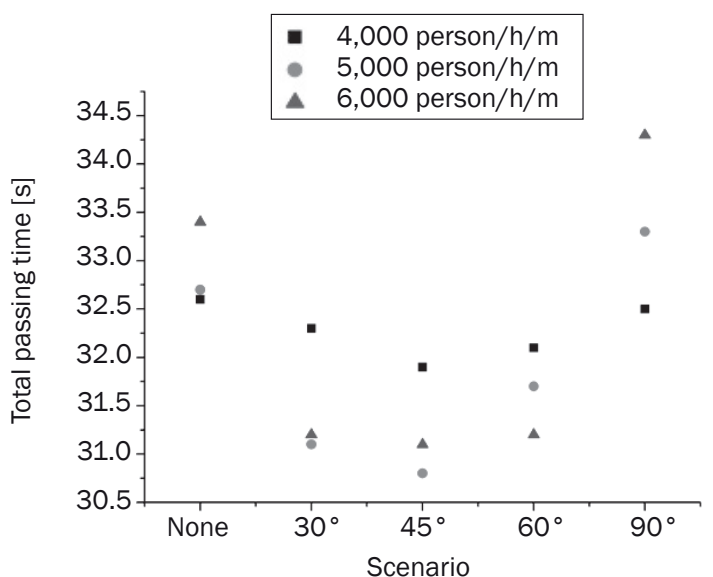

a) Total passing time

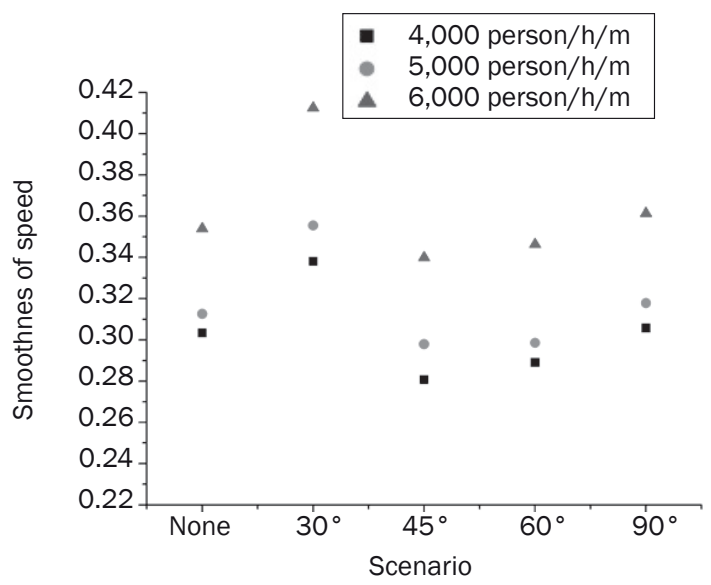

c) Smoothness of speed

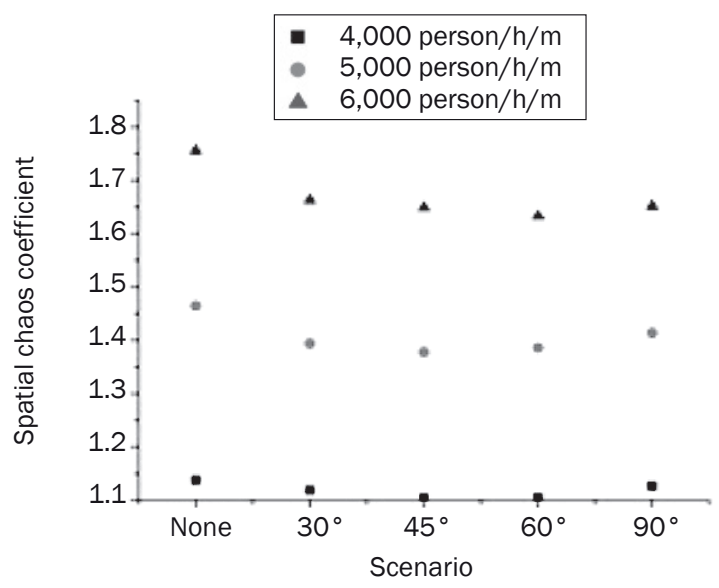

e) Spatial chaos coefficient

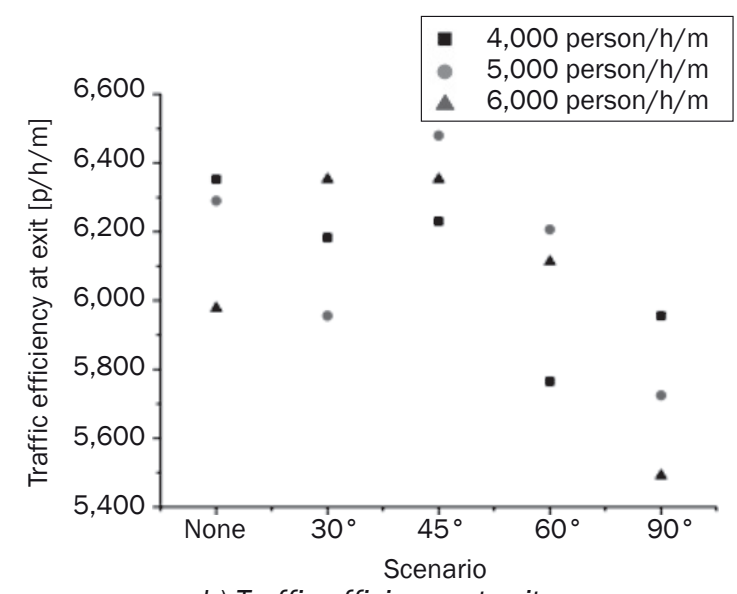

b) Traffic efficiency at exit

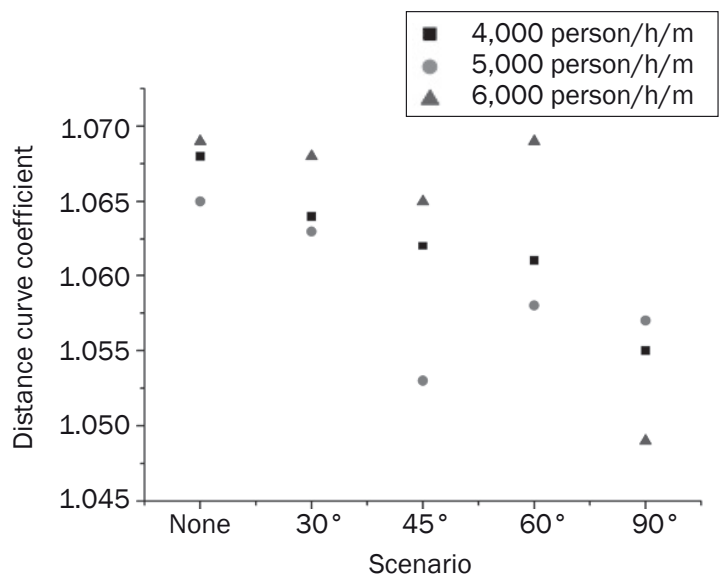

d) Distance curve coefficient

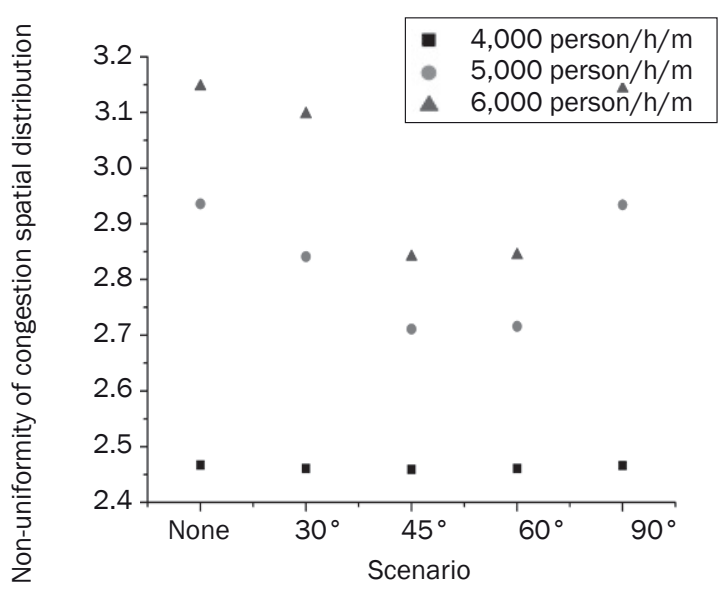

f) Non-uniformity of congestion spatial distribution

Figure 6 - Efficiency, comfort of straight funnel shape

The smoothness of speed and distance curve coefficient are much lower than the blank control group at the surface funnel under the three volumes. The smoothness of speed at the concave funnel is the lowest, 9.81\%, $8.96 \%$, and $6.31 \%$ lower than the blank control group under $4,000 \mathrm{p} / \mathrm{m} / \mathrm{h}, 5,000 \mathrm{p} / \mathrm{m} / \mathrm{h}$, and 6,000 $\mathrm{p} / \mathrm{m} / \mathrm{h}$, respectively. The distance curve coefficient in the concave funnel is the lowest, i.e., 1.69\%, 1.78\%, and $1.12 \%$ lower than blank control group under 4,000 $\mathrm{p} / \mathrm{m} / \mathrm{h}, 5,000 \mathrm{p} / \mathrm{m} / \mathrm{h}$, and $6,000 \mathrm{p} / \mathrm{m} / \mathrm{h}$, respectively.

The spatial chaos coefficient and non-uniformity of congestion spatial distribution are lower than blank control group at the surface funnel under the three volumes. The greater the volume, the more the 


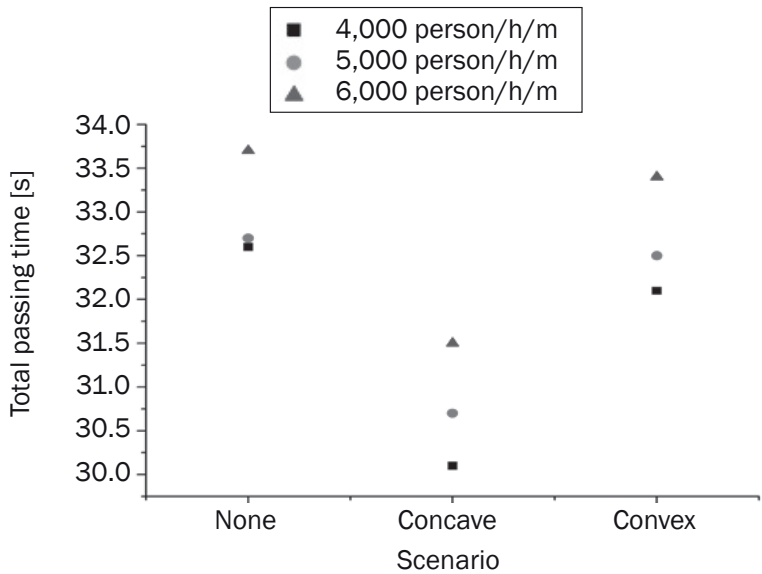

a) Total passing time

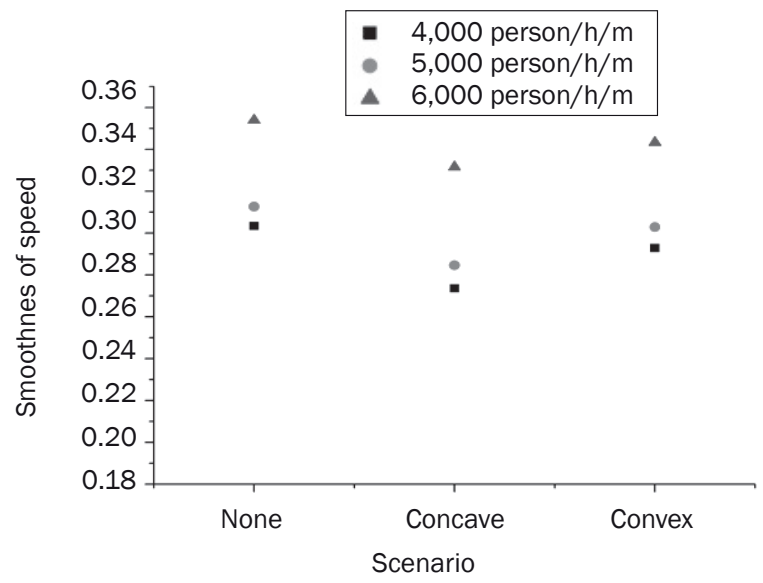

c) Smoothness of speed

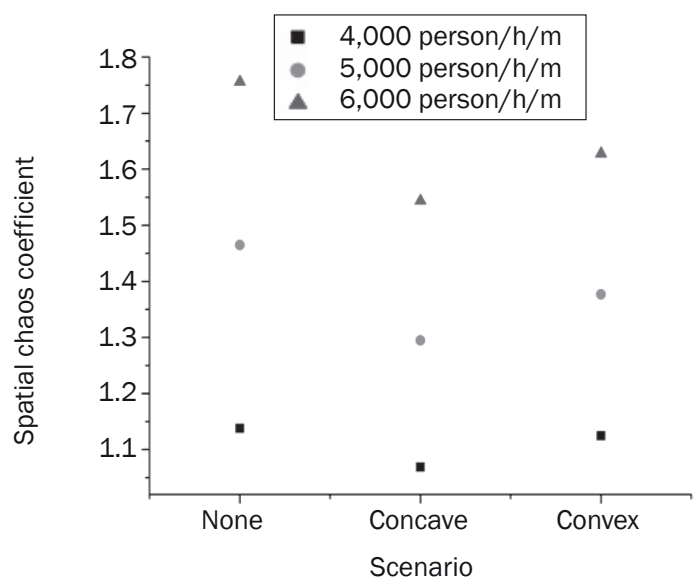

e) Spatial chaos coefficient

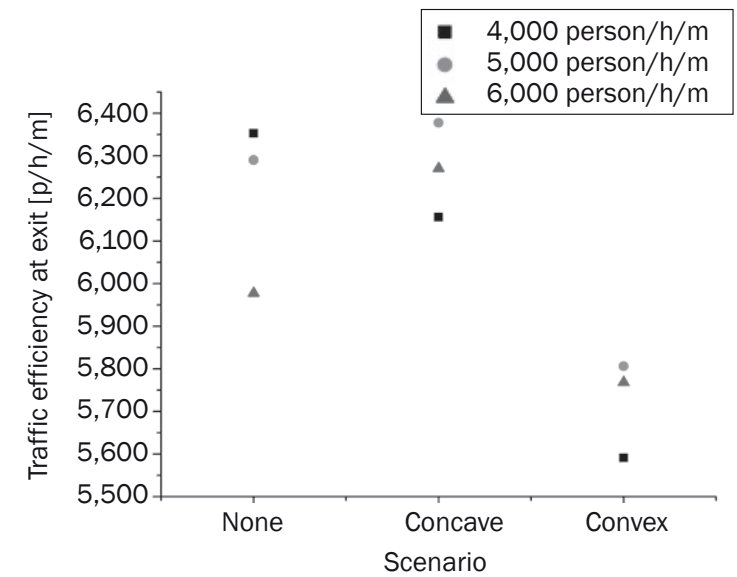

b) Traffic efficiency at exit

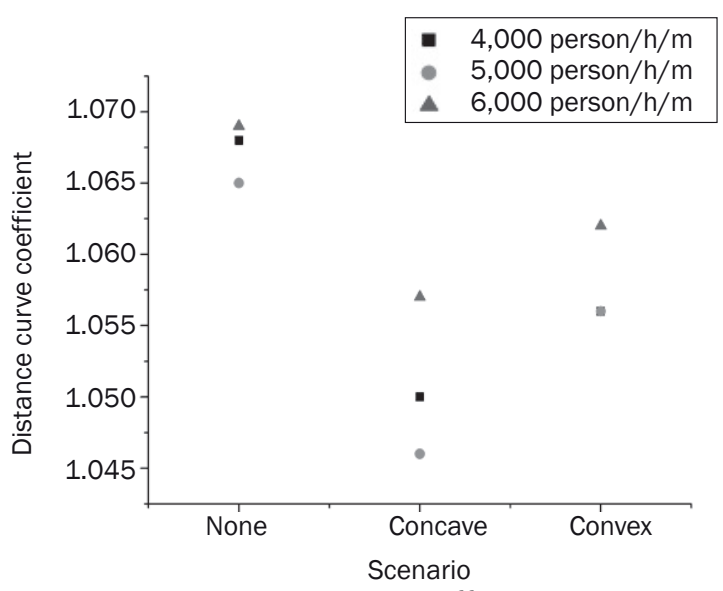

d) Distance curve coefficient

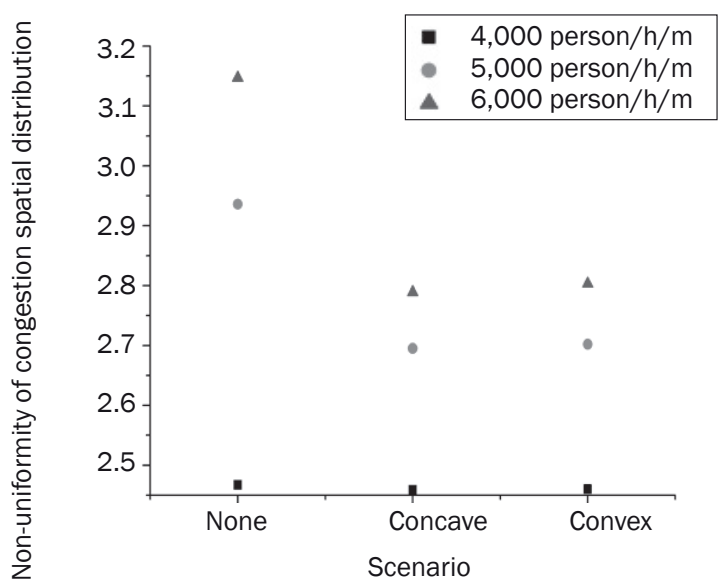

f) Non-uniformity of congestion spatial distribution

Figure 7 - Efficiency of surface funnel shape

security index reduces. The spatial chaos coefficient in the concave funnel is the lowest, $6.06 \%, 11.60 \%$, and $12.07 \%$ lower than blank control group under 4,000 $\mathrm{p} / \mathrm{m} / \mathrm{h}, 5,000 \mathrm{p} / \mathrm{m} / \mathrm{h}$ and $6,000 \mathrm{p} / \mathrm{m} / \mathrm{h}$, respectively. The non-uniformity of congestion spatial distribution in the concave funnel is the lowest too, i.e., $0.32 \%, 8.21 \%$, and $11.38 \%$ lower than the blank control group under $4,000 \mathrm{p} / \mathrm{m} / \mathrm{h}, 5,000 \mathrm{p} / \mathrm{m} / \mathrm{h}$ and $6,000 \mathrm{p} / \mathrm{m} / \mathrm{h}$, respectively.

\subsection{Column obstacle}

Figures $8 a-8 f$ show the efficiency, comfort, and security of the column obstacle under different volumes, respectively, and the different scatter values represent different volumes. The column obstacle has an effect on the evaluation index, and the influence degree is closely related to position. The total passing time is the lowest for the column on the left, $7.98 \%, 6.73 \%$, and 


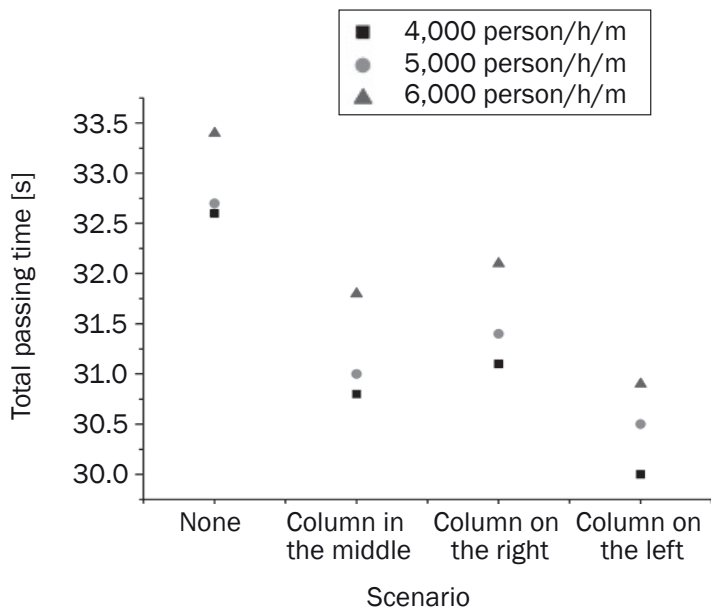

a) Total passing time

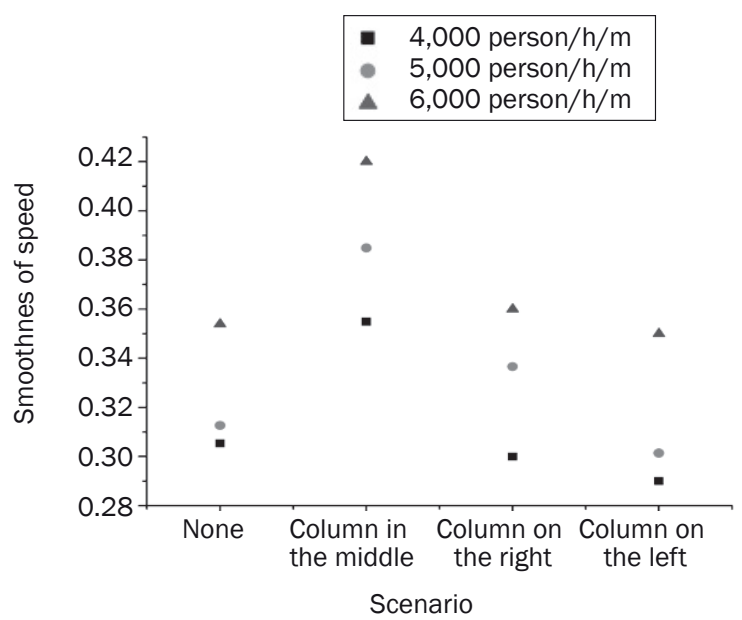

c) Smoothness of speed

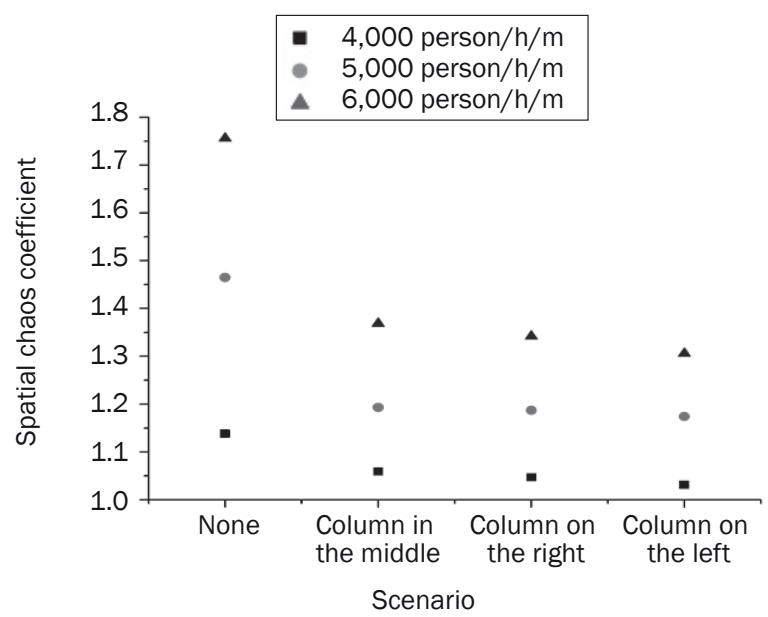

e) Spatial chaos coefficient

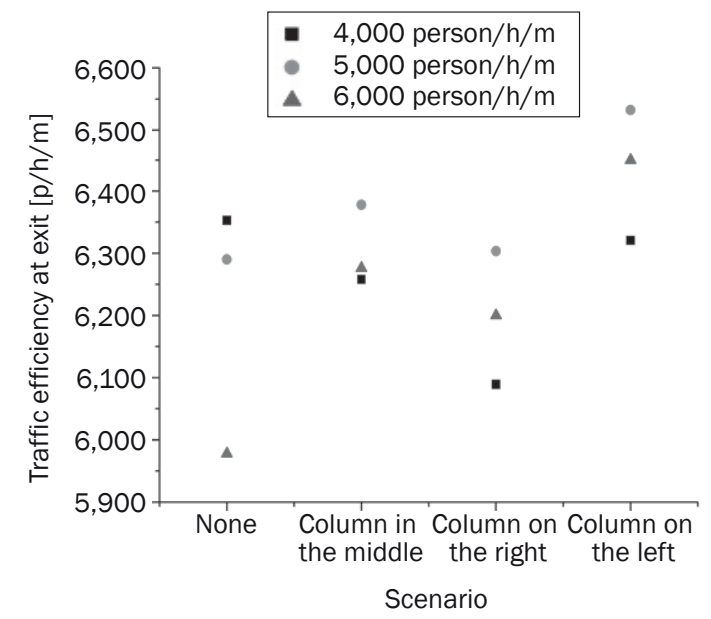

b) Traffic efficiency at exit

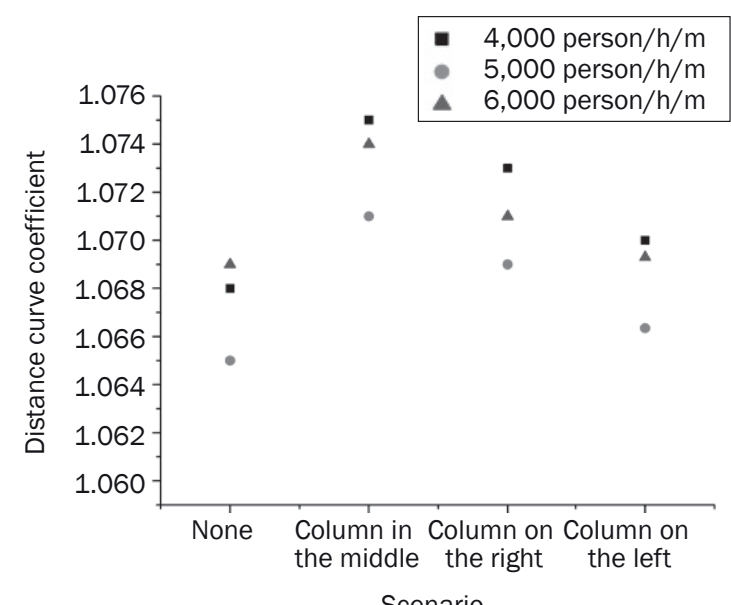

d) Distance curve coefficient

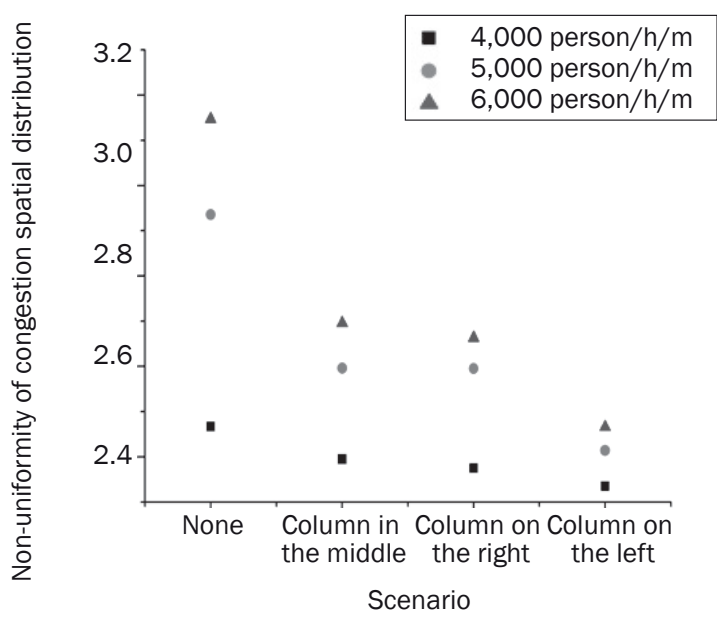

f) Non-uniformity of congestion spatial distribution

Figure 8 - Efficiency of column obstacle

7.49\% lower than the blank control group under 4,000 $\mathrm{p} / \mathrm{m} / \mathrm{h}, 5,000 \mathrm{p} / \mathrm{m} / \mathrm{h}$, and $6,000 \mathrm{p} / \mathrm{m} / \mathrm{h}$, respectively. That is related to pedestrians' tendency toward righthand walking. When the volume is comparatively small $(4,000 \mathrm{p} / \mathrm{m} / \mathrm{h})$, the column obstacle has a negative impact on traffic efficiency at exit, which is lower than the blank control group. However, when the volume is comparatively large $(5,000 \mathrm{p} / \mathrm{m} / \mathrm{h}$ and $6,000 \mathrm{p} / \mathrm{m} / \mathrm{h})$, the column obstacle has a positive impact on traffic efficiency at exit. The traffic efficiency at exit is the high- 
est at the column on the left, i.e., $3.85 \%$ and $7.90 \%$ higher than blank control group under $5,000 \mathrm{p} / \mathrm{m} / \mathrm{h}$ and $6,000 \mathrm{p} / \mathrm{m} / \mathrm{h}$, respectively.

Under all volumes, the column in the middle has a negative impact on the smoothness of speed, which is higher than the blank control group. At the same time, the column on the right has a positive impact on the smoothness of speed only under 4,000 p/m/h, 1.11\% lower than the blank control group. However, the column on the left has a positive impact on the smoothness of speed under $4,000 \mathrm{p} / \mathrm{m} / \mathrm{h}, 5,000 \mathrm{p} / \mathrm{m} / \mathrm{h}$, and $6,000 \mathrm{p} / \mathrm{m} / \mathrm{h}$, that is, $4.41 \%, 3.59 \%$, and $1.11 \%$ lower than the blank control group, respectively. The smaller the volume, the lower the smoothness of speed. Due to increased detour distance in column obstacles, the distance curve coefficient for the column obstacle is higher than blank control group. It can be seen that the column obstacle has a lower comfort degree.

Due to increased detour distances in column obstacles, pedestrians no longer stack at the bottleneck entrance. The spatial chaos coefficient and non-uniformity of congestion spatial distribution are both much

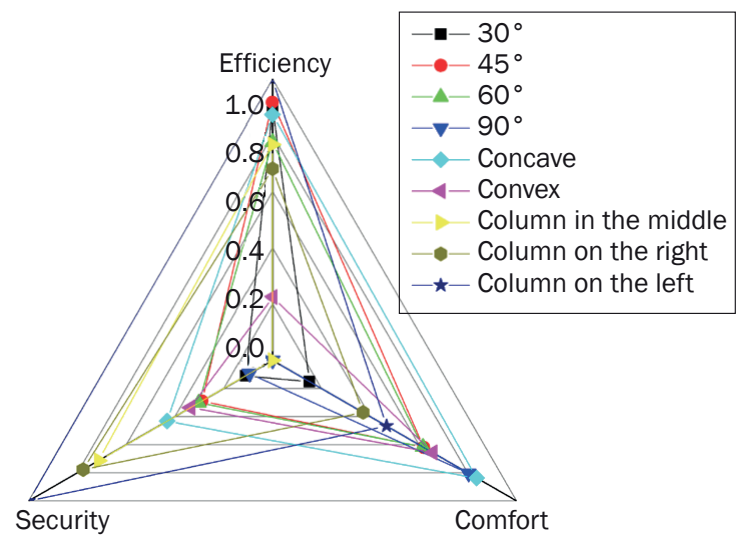

a) Under $4,000 \mathrm{p} / \mathrm{m} / \mathrm{h}$ lower than the blank control group. The spatial chaos coefficient reaches the lowest point for the column on the left, i.e., 9.40\%, 19.86\%, and 25.63\% lower than blank control group under $4,000 \mathrm{p} / \mathrm{m} / \mathrm{h}, 5,000 \mathrm{p} / \mathrm{m} / \mathrm{h}$ and $6,000 \mathrm{p} / \mathrm{m} / \mathrm{h}$, respectively. Likewise, the non-uniformity of congestion spatial distribution reaches the lowest point at the column on the left, 5.35\%, 17.78\%, and $21.64 \%$ lower than the blank control group under $4,000 \mathrm{p} / \mathrm{m} / \mathrm{h}, 5,000 \mathrm{p} / \mathrm{m} / \mathrm{h}$, and $6,000 \mathrm{p} / \mathrm{m} / \mathrm{h}$, respectively. In conclusion, the column obstacle has a higher degree of security.

\subsection{Summary}

The equal-weighted index as an efficient solution for multi-index programming problems is used to calculate accuracy. The scale of the equal-weighted index is from 0 to 1 , where 0 indicates the worst traffic effectiveness scenario, and 1 indicates the best traffic effectiveness scenario. Note that it is a relative measure, rather than absolute. Through reciprocal, contrary index is converted to forward index.

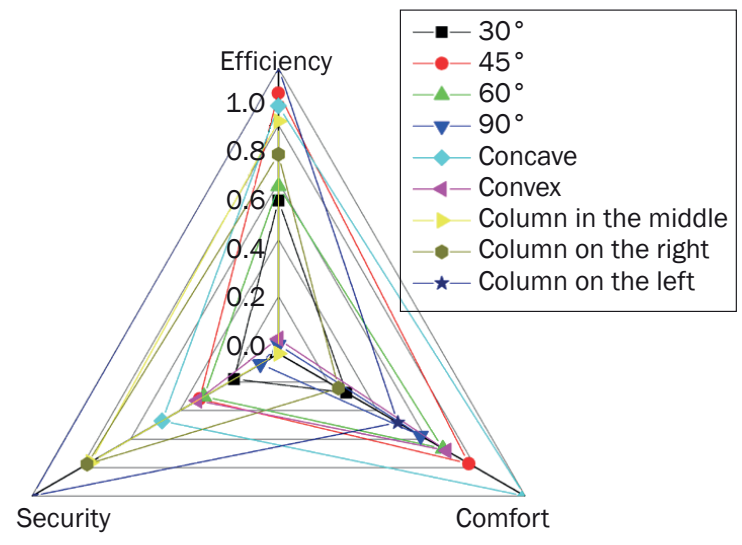

b) Under $5,000 \mathrm{p} / \mathrm{m} / \mathrm{h}$

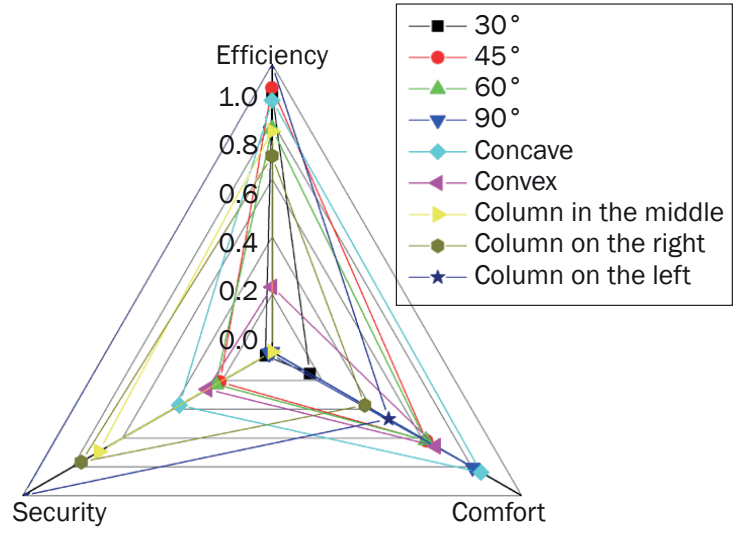

c) Under $6,000 \mathrm{p} / \mathrm{m} / \mathrm{h}$

Figure 9 - The evaluation index with equal-weighted values under different measures 
Table 3 - Scores of comprehensive assessment under different measures

\begin{tabular}{||l|c|c|c|c|c||}
\hline \multirow{2}{*}{ Optimization measures } & Scenario & Settings & $\begin{array}{c}4,000 \\
{[\mathrm{p} / \mathrm{h} / \mathrm{m}]}\end{array}$ & $\begin{array}{c}5,000 \\
{[\mathrm{p} / \mathrm{h} / \mathrm{m}]}\end{array}$ & $\begin{array}{c}6,000 \\
{[\mathrm{p} / \mathrm{h} / \mathrm{m}]}\end{array}$ \\
\hline \hline None (blank control group) & $0-1$ & - & 0.31 & 0.31 & 0.27 \\
\hline \multirow{3}{*}{ Straight funnel shape } & $1-1$ & $30^{\circ}$ & 0.28 & 0.31 & 0.36 \\
\cline { 2 - 7 } & $1-2$ & $45^{\circ}$ & 0.47 & 0.65 & 0.58 \\
\cline { 2 - 7 } & $1-3$ & $60^{\circ}$ & 0.34 & 0.50 & 0.54 \\
\cline { 2 - 7 } & $1-4$ & $90^{\circ}$ & 0.32 & 0.20 & 0.27 \\
\hline \multirow{3}{*}{ Surface funnel shape } & $2-1$ & Concave & 0.68 & 0.77 & 0.69 \\
\cline { 2 - 7 } & $2-2$ & Convex & 0.26 & 0.33 & 0.38 \\
\cline { 2 - 7 } & $3-1$ & Column in the middle & 0.47 & 0.52 & 0.49 \\
\cline { 2 - 7 } & $3-2$ & Column on the right & 0.58 & 0.57 & 0.61 \\
\cline { 2 - 7 } & $3-3$ & Column on the left & 0.82 & 0.83 & 0.82 \\
\hline
\end{tabular}

$u_{j}^{\prime}=\frac{1}{u_{j}}$

where $u_{j}^{\prime}$ is the forward index after conversion, and $u_{j}$ is the contrary index.

Then, through min-max normalization, the evaluation index is normalized.

$x^{*}=\frac{x-\min }{\max -\min }$

where $x^{*}$ is the evaluation index after normalization, $x$ is the original index, $\min$ is the minimum of the sample data, and $\max$ is the maximum of the sample data.

Figure 9 shows the equal-weighted values of an evaluation index of different measures.

- Using the straight funnel shape, with the increase of the angle, the efficiency, comfort, and security first increased and then decreased. The best funnel angle was between $30^{\circ}$ and $60^{\circ}$. Specifically, the $90^{\circ}$ funnel is not recommended. The larger the volume, the optimization is more obvious.

- Using the surface funnel shape, the shape of the surface had an effect on the efficiency, comfort, and security. The convex shape provided less optimization than the concave shape, and even negative effects under $4,000 \mathrm{p} / \mathrm{h} / \mathrm{m}$.

- Using the column obstacle, the location of the obstacle had an impact on the efficiency, comfort, and security. Setting the obstacle on the left provided higher efficiency and security than in other locations. However, its comfort is lower compared to other measures.

In summary, the efficiency, comfort, and security under the straight funnel shape were all relatively high; the efficiency and security under the surface funnel shape and column obstacle were all relatively high, but the comfort was low. Moreover, the comprehensive assessment of the column on the left showed the highest scores, meaning that it achieved optimal results.

\section{CONCLUSIONS AND RECOMMENDATIONS}

This study explores adding various measures at bottlenecks. Different measures at different volumes were investigated with pedestrian experiments which were conducted under controllable circumstances, strongly purpose-oriented, and could change between different optimization measures easily. This study proposes three optimization measures for traffic effectiveness at the bottleneck. The measures were evaluated according to passenger flow level and priorities of efficiency, comfort, and security. When efficiency or security come first, the column on the left is recommended. However, this might be caused by the righthand traffic in China, therefore column on the left is recommended in countries or regions with right-hand traffic. When comfort is the priority, the concave funnel is recommended. When comprehensiveness comes first, the column on the left is recommended, which is also more suitable for countries or regions with righthand traffic. The findings of this study can be used in rail transit design and management to optimize inevitable bottleneck facilities. However, the limitations of this study are that the experimented bottleneck was only $1 \mathrm{~m}$ wide, and the corridor was $6 \mathrm{~m}$ wide. In addition, only the unidirectional flow was studied. In future studies, more fundamental dimensions, more types of population, as well as bidirectional flow, could be taken into consideration.

\section{ACKNOWLEDGEMENT}

The authors would like to acknowledge the financial support for this study provided by the National Natural Science Foundation of China (No. 51308017), Key Program of Beijing Municipal Natural Science Foundation 
(No. 4181002), Beijing Nova Program (Grant No. Z141106001814110), and Science and Technology Program of Beijing (Grant No. D161100005616001).

罗薇 ${ }^{1}$, 在读博士, 邮箱: luoweibjut@163.com

孙立山 ${ }^{1}$, 博士, 邮箱: Issun@bjut.edu.cn 姚丽亚 ${ }^{2 *}$, 博士, 邮箱: yaoliya@bit.edu.cn

宫庆胜 ${ }^{1}$, 邮箱: gqsgentleman@sina.com

荣建 ${ }^{1}$, 博士, 邮箱: jrong@bjut.edu.cn

1 北京工业大学, 北京市交通工程重点实验室

中国，北京市，朝阳区，平乐园100号

2 北京理工大学, 机械与车辆学院

中国, 北京市, 海淀区, 中关村南大街5号

\section{轨道站点瓶颈处行人流优化实验研究}

\section{摘要}

轨道站点瓶颈是指行人通行过程中，减少了行人流量 的狭窄区域。瓶颈处行人被迫聚集, 降低了行人换乘的通 行效率和舒适度, 严重时甚至引发踩踏等安全事故。本文 通过开展行人实验, 研究了轨道站点瓶颈处行人流优化措 施。通过分析行人流的效率、顺畅和安全, 评价和建议了 所提出的三种优化措施。其中，本文将瓶颈入口处设置直 线漏斗称为直线漏斗型, 设置曲面漏斗称为曲面漏斗型, 设置圆柱障碍物称为圆柱障碍型。研究结果表明: 当效率 或安全优先时，推荐设置左侧圆柱型措施; 当舒适优先 时, 推荐设置凹面漏斗型措施; 当需要综合考虑效率、顺 畅、安全时, 推荐设置左侧圆柱型措施。此外, 行人流量 越大, 优化效果越明显。尽管建造轨道站点时存在一些无 法避免的瓶颈，但本文提出的优化措施可提高瓶颈处行人 流的效率、顺畅和安全, 并能为轨道车站的设计和管理提 供建议，进而帮助缓解瓶颈设施的不利影响。

\section{关键词}

轨道站点; 瓶颈; 优化措施; 行人特征; 行人实验

\section{REFERENCES}

[1] Beijing Municipal Commission of Transport. Rail Transit Networks Operating Information Daily, 2015.

[2] Helbing D, Molnar P. Self-Organization Phenomena in Pedestrian Crowds. In: Helbing D. (ed.) Social Self-Organization. 1998; p. 569-577.

[3] Bolay K. Nichtlineare Phänomene in einem fluid-dynamischen Verkehrsmodell. Unpublished diploma thesis. University of Stuttgart, Stuttgart, Germany; 1998. German

[4] Helbing D, Farkas I, Vicsek T. Simulating dynamical features of escape panic. Nature. 2000;407(6803): 487-490.

[5] Helbing D, Molnár P, Farkas IJ, et al. Self-organizing pedestrian movement. Environment \& Planning $B$ : Planning \& Design. 2001;28(3): 361-383.

[6] Daamen W, Hoogendoorn S. Controlled experiments to derive walking behaviour. European Journal of Transport \& Infrastructure Research. 2003;3(1): 39-59.

[7] Hoogendoorn SP, Daamen W. Pedestrian behavior at bottlenecks. Transportation Science. 2005;39(2): 147-159.

[8] Kretz T, Grünebohm A, Schreckenberg M. Experimental study of pedestrian flow through a bottleneck.
Journal of Statistical Mechanics: Theory and Experiment. 2006;2006(5): P10014.

[9] Kretz T, Hengst S, Vortisch P. Pedestrian flow at bottlenecks - validation and calibration of vissim's social force model of pedestrian traffic and its empirical foundations. International Symposium of Transport Simulation; 2008.

[10] Seyfried A, Passon O, Steffen B, et al. New insights into pedestrian flow through bottlenecks. Transportation Science. 2007;43(3): 395-406.

[11] Guo RY. Simulation of spatial and temporal separation of pedestrian counter flow through a bottleneck. Physica A: Statistical Mechanics and its Applications. 2014;415: 428-439..

[12] Li D, Han B. Behavioral effect on pedestrian evacuation simulation using cellular automata. Safety Science. 2015;80:41-55.

[13] Liao W, Tordeux A, Seyfried A, et al. Measuring the steady state of pedestrian flow in bottleneck experiments. Physica A: Statistical Mechanics and its Applications; 2016;461: 248-261.

[14] Sun L, Gong Q, Yao L, et al. A Dynamic Time Warping Algorithm Based Analysis of Pedestrian Shockwaves at Bottleneck. Journal of Advanced Transportation. 2018;2018: 1269439

[15] Shiwakoti N, Gong Y, Shi X, et al. Examining influence of merging architectural features on pedestrian crowd movement. Safety Science. 2015;75: 15-22.

[16] Sun L, Luo W, Yao L, et al. A comparative study of funnel shape bottlenecks in subway stations. Transportation Research Part A: Policy and Practice. 2017;98: 14-27.

[17] Hoogendoorn SP, Daamen W, Bovy PHL. Extracting microscopic pedestrian characteristics from video data. Paper presented at: Transportation Research Board annual meeting, 2003 Jan 15-18, Washington, USA.

[18] Gérinlajoie M, Richards CL, McFadyen BJ. The negotiation of stationary and moving obstructions during walking: Anticipatory locomotor adaptations and preservation of personal space. Motor Control. 2005;9(3): 242-69.

[19] Fujiyama T. Investigating use of space of pedestrians (working paper). Centre for Transport Studies, UCL,London, UK; 2005.

[20] Curtis S, Manocha D. Pedestrian simulation using geometric reasoning in velocity space. In: Weidmann U, Kirsch U, Schreckenberg M. (eds) Pedestrian and Evacuation Dynamics 2012. Springer International Publishing; 2014.

[21] Cao X, Handy SL, Mokhtarian PL. The influences of the built environment and residential self-selection on pedestrian behavior: Evidence from Austin, TX. Transportation. 2006;33(1): 1-20.

[22] Townsend C, Zacharias J. Built environment and pedestrian behavior at rail rapid transit stations in Bangkok. Transportation. 2010;37(2): 317-330.

[23] Reynolds CW. Steering behaviors for autonomous characters. In: Proceedings of Game Developers Conference 1999, San Jose, California. San Francisco, California: Miller Freeman Game Group; 1999 p. 763-782.

[24] Daamen W. Modelling passenger flows in public transport facilities. Delft University Press; 2004.

[25] Song W-G, Yu Y-F, Wang B-H, et al. Evacuation behaviors at exit in $C A$ model with force essentials: $A$ 
comparison with social force model. Physica A: Statistical Mechanics and its Applications. 2006;371(2): 658-666.

[26] Daamen W, Hoogendoorn SP. Experimental research of pedestrian walking behavior. Transportation Research Record Journal of the Transportation Research Board. 2003;1828: 20-30.

[27] Seyfried A, Steffen B, Winkens A, et al. Empirical data for pedestrian flow through bottlenecks. In: Appert-Rolland C, Chevoir F, Gondret P, Lassarre S, Lebacque JP, Schreckenberg M. (eds) Traffic and Granular Flow'07. Berlin, Heidelberg: Springer; 2009.

[28] Fernández R, Valencia A, Seriani S. On passenger saturation flow in public transport doors. Transportation
Research Part A: Policy and Practice. 2015;78: 102-112.

[29] Sun L, Yang Z, Rong J, Liu X. Study on the weaving behavior of high density bidirectional pedestrian flow. Mathematical Problems in Engineering. 2014;2014(546): 1-9

[30] Yang H, Yuen RKK, Cheng X, et al. Effect of right-hand traffic rules on evacuation through multiple parallel bottlenecks. Fire Technology. 2014;50(2): 297-316.

[31] Transit Cooperative Research Program (TCRP). Transit Capacity and Quality of Service Manual. $3^{\text {rd }}$ ed.; 2003. p. 23-67.

[32] Li D, Han B. Pedestrian traffic. Beijing: China Communication Press; 2011. 